\title{
Seroprevalence and risk factors of Toxoplasma gondii infection among pregnant women attending antenatal care in Kigali, Rwanda
}

\author{
ESPERANCE MUREBWAYIRE ${ }^{*}$, KARIUKI NJANAAKE ${ }^{1}$, JEAN CLAUDE S. NGABONZIZA ${ }^{1,2}$, WALTER JAOKO ${ }^{1,3}$ \\ and KATO J. NJUNWA ${ }^{4}$ \\ 'School of Medicine and Health Sciences, University of Nairobi, Nairobi, Kenya \\ ${ }^{2}$ National Reference Laboratory Division, Rwanda Biomedical Centre, Kigali, Rwanda \\ ${ }^{3} \mathrm{KAVI}$-Institute of Clinical Research, Nairobi, Kenya \\ ${ }^{4}$ College of Medicine and Health Sciences, University of Rwanda, Kigali, Rwanda
}

\begin{abstract}
Background: Toxoplasma gondii infection in pregnancy, if left untreated, is associated with spontaneous abortions, low birth weight babies, congenital deformities and intrauterine deaths. The infection is also associated with human immune deficiency virus/acquired immunodeficiency syndrome (HIV/AIDS). In Rwanda, the burden and risk factors of T. gondii infection among pregnant women and among HIV infected pregnant women is largely unknown. This cross-sectional study aimed at determining the seroprevalence of $T$. gondii infections and their risk factors among pregnant women in Kigali, Rwanda.

Methods: Pregnant women aged 18 years and above who were attending antenatal care at four clinics in Kigali City, between April and August 2014 were screened for IgG and IgM antibodies against T. gondii using ELISA technique. Information on their HIV status and $\mathrm{CD}_{4}{ }^{+}$cell count was obtained from their medical records. Participants were also interviewed on selected behaviours that predispose individuals to T. gondii infection.

Results: A total of 384 pregnant women were involved in the study. The overall T. gondii seroprevalence was $12.2 \%$. Of the 384 pregnant women studied, 37 (9.6\%) were positive for anti-T. gondii-specific IgG antibodies, indicating past infection and 15 (3.9\%) had positive IgM results indicating recent infection. Drinking untreated water and eating undercooked meat were identified as important risk factors for $T$. gondii infection respectively at $22.4 \%$ and $22.3 \%$ [OR=3.95, $\mathrm{Cl}: 2.09-7.49 ; \mathrm{p}<0.001$ and $\mathrm{OR}=3.27,95 \% \mathrm{Cl}: 1.75-$ 6.09; $p<0.001]$.

Conclusion: Although the seroprevalence of $T$. gondii antibodies is relatively low, institution of interventional measures is desirable.
\end{abstract}

Keywords: Toxoplasma gondii, seroprevalence, pregnancy, risk factors, Rwanda

\section{Introduction}

Toxoplasma gondii is an obligate intracellular protozoan parasite that causes toxoplasmosis (Jones et al., 2001). It is estimated that about one third of the world's population is infected with $T$. gondii (Pappas et al., 2009). In Africa, overall seroprevalence rate as high as 92.5\% has been reported (Ayi et al., 2009). However, the prevalence of infection varies widely between countries (from 10\% to $80 \%$ ) and often within a given country or between different communities in the same region (Pappas et al., 2009). The variations in socio-economic factors between communities and countries have been described to account for the observed difference in prevalence (Rosso et al., 2008; Fernando et al., 2008).

Majority of horizontal transmissions to humans is due to either the ingestion of tissue cysts in infected meat or by the ingestion of soil, water, or food contaminated with sporulated oocysts from the environment or, less frequently, directly from feline faeces (Foulon et al., 1999). Transplacental transmission occurs when an immunocompetent woman acquires a primary infection during pregnancy (Hegab \& Al-Mutawa, 2003), or may also be due to a reactivated infection in immunocompromised women (Dubey \& Jones, 2008). Congenital infection can lead to a wide variety of manifestations in the foetus and infant including spontaneous abortion, still-birth, hydrocephalus or microcephalus, cerebral calcifications and retinochoroiditis (Gibbs, 2002; Goldenberg \& Thompson, 2003).

\footnotetext{
${ }^{*}$ Correspondence E-mail: mespe2013@gmail.com
} 
Seroprevalence of $T$. gondii among pregnant women has been studied by different researchers. A study done in Mwanza, Tanzania, showed a seroprevalence of 30.9\% for T. gondiispecific antibodies (Mwambe et al., 2013), while in Nigeria expectant women were reported to have a seroprevalence of $7.6 \%$ and $32.6 \%$ for Toxoplasma IgM and Toxoplasma IgG respectively (DejiAgboola et al., 2011). Despite the fact that $T$. gondii infection in pregnancy is associated with significant morbidities, serological screening of pregnant women for this infection is however, not routinely carried out during antenatal care in Rwanda. As a result, little is known about the prevalence and risk factors of the parasite among pregnant women in the country. Thus, the objective of the present study was to determine the seroprevalence of $T$. gondii infections among pregnant women attending selected antenatal clinics in Rwanda and risk factors associated with the acquisition of the infection.

\section{Materials and Methods}

\section{Study area and population}

This cross-sectional e study was conducted in Kigali, Rwanda in four selected public Health Centres namely Biryogo, Cor-Unum, Muhima and Nyarugunga between April to August 2014. The Health Centres were selected because they were located in the central part of Kigali city and therefore likely to attract different categories of the population. The study population was all the pregnant women aged 18 years and above who were attending antenatal care at these health centres during the study period. Excluded from the study were non-pregnant women, and pregnant women who were below the age of 18 years.

\section{Sample size and sampling procedures}

The sample size of 384 pregnant women was calculated by using the formula by Cochran (1963) with an estimated prevalence ( $p$ ) of $50 \%$. The eligible women were requested to enrol into the study voluntarily on the day of their antenatal visit. The enrolment continued until the sample size of 384 was reached. Demographic data consisting of age, residence, occupation, marital status, education, and relevant clinical information such as gravidity and trimester were collected using a standardized data collection tool.

\section{Sample collection and laboratory processing}

About $5 \mathrm{ml}$ of venous blood was collected aseptically from each of the 384 pregnant women and transported to the National Reference Laboratory (NRL) in Kigali. At the NRL plasma was prepared from the whole blood by centrifugation at 3,000 rpm for 5 minutes and assayed for anti- $T$. gondii antibodies (IgM and IgG) using bio ELISA TOXO IgG \& IgM kits (Biokit, Spain, Lot Number B 23643), according to the manufacturer's instructions.

A volume of $10 \mu \mathrm{l}$ of test serum was diluted using $1 \mathrm{ml}$ of sample diluent and the diluted specimen incubated in microplate wells coated with rabbit antibodies anti-human IgM or IgG. The wells were then washed using washing solution to remove residual test sample, and $100 \mu \mathrm{l}$ of Toxoplasma antigen labelled with peroxidase was added. The plates were then washed again using washing solution to eliminate unbound material. Furthermore, $100 \mu \mathrm{l}$ of solution of enzyme substrate and chromogen were added. This solution developed a blue colour if the sample contained anti-T. gondii IgM or IgG. The blue colour changed to yellow after blocking the reaction with sulphuric acid. The plates were then read using an ELISA reader at $450 \mathrm{~nm}$ wavelength. The concentration of antibodies in the sample was then determined by means of a calibration curve.

The cut-off value of the assay was calculated and results were expressed in an index by dividing sample absorbance by the cut-off value. The test was considered negative if the index was $<0.9$, the result was equivocal when index was from 0.9 to $<1.0$ while a positive result was indicated if the index was $\geq 1.0$. A negative reaction was judged as indicative of the absence of significant Toxoplasma antibodies. A positive Toxoplasma IgG reaction was interpreted as an indication of 
either a past or recent infection. Information on HIV status and CD4+ cell count of the participants was obtained from their medical records.

\section{Data analysis}

Data collected were checked for completeness and consistency and were entered into a computer and analysed using SPSS version 17.0 software package. Likely association between the sociodemographic characteristics of participants and sero-positivity was assessed using a Chi-square test. To determine which of the characteristics could be having independent influence on observed $T$. gondii sero-positivity, those that were found to have a $\mathrm{p}$-value of $<0.2$ were taken into the univariable and multivariable models. The manual backward-stepwise elimination of factors was used to develop a final model until the remaining variables were significant at $p$-value $<0.05$.

\section{Ethical considerations}

Ethical clearance was obtained from Kenyatta National Hospital-University of Nairobi Ethics and Research Committee and Rwanda National Ethics Committee. Permission was obtained from relevant authorities in all respective study sites before beginning the study. Written informed consent was sought from pregnant woman prior to involvement in the study. Only those who agreed to participate by signing the informed consent form were included in the study Information about each study participant was kept confidential and venous blood specimens were stripped of all personal identification.

\section{Results}

A total of 384 pregnant women were enrolled during the study period. The median age of the study population was 27 years (range $=18$ to 45 years). Most women (51.0\%) were aged between 26 and 35 years. Over half (57.8\%) of the study subjects were single, $63.5 \%$ were unemployed, and $64.1 \%$ were multigravidae with $54 \%$ on second trimester of their pregnancy. Majority of women $(71.1 \%)$ had primary education, and only (25.0\%) had attained a higher level of education (Table 1 ).

Table 1: Social-demographic and clinical characteristics of pregnant women $(\mathrm{N}=384)$

\begin{tabular}{llll}
\hline Variable & Response & Number & Percentage \\
\hline Age & $18-25$ & 156 & 40.6 \\
& $26-35$ & 193 & 50.3 \\
Marital status & $36-45$ & 35 & 9.1 \\
Occupation & Married & 162 & 42.2 \\
& Single & 222 & 57.8 \\
Level of education & Employed & 140 & 36.5 \\
& Not employed & 244 & 63.5 \\
Gravidity & None & 15 & 3.9 \\
Trimester of pregnancy & Primary & 273 & 71.1 \\
& Secondary and above & 96 & 25.0 \\
HIV status & Primigravida & 138 & 35.9 \\
& Multigravida & 246 & 64.1 \\
Water type & First & 80 & 20.8 \\
& Second & 207 & 54.0 \\
Own a cat & Third & 97 & 25.2 \\
& Negative & 365 & 95.0 \\
Under cooked meat & Positive & 19 & 5.0 \\
& Treated & 250 & 65.1 \\
& Untreated & 134 & 34.9 \\
& No & 345 & 89.8 \\
& Yes & 39 & 10.2 \\
Non & No & 272 & 70.8 \\
& Yes & 112 & 29.2
\end{tabular}




\begin{tabular}{|c|c|c|c|}
\hline \multirow[t]{2}{*}{ Eat in restaurant } & No & 220 & $57 \cdot 3$ \\
\hline & Yes & 164 & 42.7 \\
\hline \multirow[t]{2}{*}{ Taste food } & No & 97 & $25 \cdot 3$ \\
\hline & Yes & 278 & 74.7 \\
\hline \multirow[t]{2}{*}{ Had experience abortion } & No & 311 & 81.0 \\
\hline & Yes & 73 & 19.0 \\
\hline \multirow[t]{2}{*}{ Knowledge on Toxoplasma gondii } & No & 375 & 97.7 \\
\hline & Yes & 9 & 2.3 \\
\hline
\end{tabular}

Overall, out of the 384 pregnant women studied, 47 were sero-positive giving a sero-prevalence of T. gondii of $12.2 \%$. A total of $37(9.6 \%)$ were positive for anti-T. gondii-specific IgG antibodies, indicating past infection and $15(3.9 \%)$ had positive IgM results indicating recent infection. Of all the characteristics of pregnant women studied, significant association with sero-positivity was found only in water used for drinking $\left(\chi^{2}=19.73 ; p<0.001\right)$ and consuming undercooked meat $\left(\chi^{2}=14.96\right.$, $\mathrm{p}<0.001$ ) (Tablez).

Table 2: Chi-squared and Fisher's exact tests of characteristics for association with sero-positivity of $T$. gondii

\begin{tabular}{|c|c|c|c|c|c|}
\hline Variable & Response & No. Positive (\%) & No. Negative (\%) & $x^{2}$ & p-value \\
\hline \multirow[t]{3}{*}{ Age (years) } & $18-25$ & $18(11.5)$ & $138(88.5)$ & 0.87 & 0.65 \\
\hline & $26-35$ & $23(11.9)$ & $170(88.1)$ & & \\
\hline & $36-45$ & $6(17.1)$ & $29(82.9)$ & & \\
\hline \multirow[t]{2}{*}{ Marital Status } & Married & $19(11.7)$ & $143(88.3)$ & 0.07 & 0.79 \\
\hline & Not Married & $28(12.6)$ & $194(87.8)$ & & \\
\hline \multirow[t]{2}{*}{ Occupation } & Unemployed & $30(12.3)$ & 214(87.7) & 0.0 & 0.96 \\
\hline & Employed & $17(12.1)$ & $123(87.9)$ & & \\
\hline \multirow[t]{3}{*}{ Education } & None & $4(26.7)$ & $11(73.3)$ & 3.21 & 0.2 \\
\hline & Primary & $33(21.1)$ & $240(87.9)$ & & \\
\hline & $\geq$ Secondary & $10(10.4)$ & $86(89.6)$ & & \\
\hline \multirow[t]{2}{*}{ Gravidity } & Primigravida & $17(12.3)$ & $121(87.7)$ & 0.0013 & 0.97 \\
\hline & Multigravida & $30(12.2)$ & $216(87.8)$ & & \\
\hline \multirow[t]{3}{*}{ Trimester of pregnancy } & First & $8(10.0)$ & $72(90.0)$ & 0.5154 & 0.77 \\
\hline & Second & $26(12.6)$ & $181(87.4)$ & & \\
\hline & Third & $13(13.4)$ & $84(86.6)$ & & \\
\hline \multirow[t]{2}{*}{ HIV status } & Negative & $46(12.6)$ & $319(87.4)$ & & 0.49 \\
\hline & Positive & $1(5 \cdot 3)$ & $18(94.7)$ & & \\
\hline \multirow[t]{2}{*}{ Water treatment } & Treated & $17(6.8)$ & $233(93.2)$ & 19.73 & $<0.001$ \\
\hline & Untreated & $30(22.4)$ & $104(77.6)$ & & \\
\hline \multirow[t]{2}{*}{ Cat ownership } & No & $44(12.8)$ & $301(87.2)$ & & 0.45 \\
\hline & Yes & $3(7.7)$ & $36(92.3)$ & & \\
\hline \multicolumn{6}{|l|}{ Consumption of } \\
\hline \multirow[t]{2}{*}{ undercooked meat } & No & $22(8.1)$ & $250(91.9)$ & 14.96 & $<0.001$ \\
\hline & Yes & $25(22.3)$ & $87(77.7)$ & & \\
\hline \multirow[t]{2}{*}{ Eat in restaurant } & No & $21(9.5)$ & $199(90.5)$ & 3.48 & 0.062 \\
\hline & Yes & $26(15.9)$ & $138(84.1)$ & & \\
\hline \multirow[t]{2}{*}{ Taste cooking food } & No & $16(16.5)$ & $81(83.5)$ & 2.19 & 0.14 \\
\hline & Yes & $31(10.8)$ & $256(89.2)$ & & \\
\hline \multirow[t]{2}{*}{ Experienced abortion } & No & $35(11.3)$ & $276(88.7)$ & 1.48 & 0.224 \\
\hline & Yes & $12(16.4)$ & $61(83.6)$ & & \\
\hline \multirow{3}{*}{$\begin{array}{l}\text { Knowledge of } \\
\text { toxoplasmosis }\end{array}$} & & & & & \\
\hline & No & 0 & $9(100)$ & & 0.608 \\
\hline & Yes & $47(12.5)$ & $328(87.5)$ & & \\
\hline
\end{tabular}

In univariable analysis higher risk of infection with $T$. gondii increased with drinking untreated water (OR 3.95, $\mathrm{Cl}$ 2.09-7.49); and consumption of undercooked meat (OR 3.27, $\mathrm{Cl}$ 1.75-6.09). Eating in restaurant, and tasting cooking remained statistically not significant at $p<0.05$. Since they had a $\mathrm{p}<0.2$ they were put in a multivariable logistic model along with the significantly associated variables (Table 3). Still, significantly associated with $T$. gondii sero-positivity were the drinking of 
untreated water (Adjusted OR 4.01, $\mathrm{Cl} 2.08-7.69, p<0.001$ ) and consumption of undercooked meat (Adjusted OR 3.27, Cl 1.75-6.09, $\mathrm{p}<0.001$ ).

Table 3: Logistic regression of variables significantly associated with $\mathrm{T}$. gondii sero-prevalence $(\mathrm{N}=384)$

\begin{tabular}{|c|c|c|c|c|c|c|c|}
\hline \multirow[t]{2}{*}{ Variable } & \multirow[t]{2}{*}{ Response } & \multirow{2}{*}{$\begin{array}{l}\text { Positive } \\
\text { (\%) }\end{array}$} & \multirow{2}{*}{$\begin{array}{l}\text { Negative } \\
(\%)\end{array}$} & \multirow{2}{*}{$\begin{array}{l}\text { Univariable } \\
\operatorname{COR}(95 \% \mathrm{Cl})\end{array}$} & \multicolumn{3}{|c|}{ Multivariable } \\
\hline & & & & & P-value & $\operatorname{AOR}(95 \% \mathrm{Cl})$ & P-value \\
\hline \multirow{2}{*}{$\begin{array}{l}\text { Water } \\
\text { treatment }\end{array}$} & Treated & $17(6.8)$ & $233(93.2)$ & 1 & & 1 & \\
\hline & Untreated & $30(22.4)$ & $104(77.6)$ & $3.95(2.09-7.49)$ & $<0.001$ & $\begin{array}{l}4.01(2.08- \\
7.69)\end{array}$ & $<0.001$ \\
\hline \multirow{2}{*}{$\begin{array}{l}\text { Eating of } \\
\text { undercooked } \\
\text { meat }\end{array}$} & No & $22(8.1)$ & 250(91.9) & 1 & & 1 & \\
\hline & Yes & $25(22.3)$ & $87(77 \cdot 7)$ & $3.27(1.75-6.09)$ & $<0.001$ & $\begin{array}{l}3.32(1.74- \\
6.32)\end{array}$ & $<0.001$ \\
\hline \multirow{2}{*}{$\begin{array}{l}\text { Eat in } \\
\text { restaurant }\end{array}$} & No & $21(9 \cdot 5)$ & 199(90.5) & 1 & & & \\
\hline & Yes & $26(15.9)$ & $138(84.1)$ & $1.79(0.97-3 \cdot 3)$ & 0.062 & & \\
\hline \multirow{2}{*}{$\begin{array}{l}\text { Taste } \\
\text { cooking food }\end{array}$} & No & $16(16.5)$ & $81(83.5)$ & 1 & & & \\
\hline & Yes & $31(10.8)$ & $256(89.2)$ & $0.61(0.31-1.18)$ & 0.14 & & \\
\hline
\end{tabular}

Key: $\mathrm{COR}=$ Crude Odds Ratio; $\mathrm{AOR}=$ Adjusted Odds Ratio; $\mathrm{Cl}=$ Confidence Interval

\section{Discussion}

Few studies have reported on seroprevalence of anti-T. gondii in Rwanda and none on pregnant women. The present study found an overall sero-prevalence of $12.2 \%$ for anti-T. gondii antibody among pregnant women attending antenatal clinics in Kigali, Rwanda. This rate is lower than the range of $25 \%$ to $92.5 \%$ seroprevalence among pregnant women reported elsewhere in Africa (Mwambe et al., 2013; Alsammani, 2016). Various factors have been attributed to disparity in locality seroprevalence rates of $T$. gondii including, among others temperature, humidity, wind, where cooler weather conditions as found in Kigali would relatively disfavour the thriving of the parasite (Tenter et al., 2000). Such regional variation of seroprevalence of $T$. gondii infection has previously been described (Jones et al., 2001; Mwambe et al., 2013). In addition, the observed differences in seroprevalence of anti-T. gondii infection may be due to cultural variations in the populations. Likewise, socio-economic status, education, sanitary conditions and differences in dietary habits may contribute to observed differences in sero-positivity (Petersen et al. 2010).

Surprisingly, in the present study, there was a non-statistically significant increase in seropositivity of anti-T. gondii antibody with age of study participants. However, the observation is in agreement with other similar studies in which increasing age was more associated with chronic infection (Rosso et al., 2008, Al-Mohammad et al., 2010; Markovich et al., 2014). This could be explained by the fact that older women are more likely to have been exposed much longer to any one of the risk factors than younger women.

Corroborating many other studies, the use of untreated water was found to increase the risk of infection with T. gondii (Mwambe et al., 2013; Alsammani, 2014) through the ingestion of oocysts in contaminated water. A higher prevalence of $T$. gondii infection has been found among pregnant women who drink water from the well than those who drink piped water (Ishaku et al., 2009). A similar finding showing an association between prevalence of $T$. gondii infection and source of drinking water has been reported from Brazil (Bahia-Oliveira et al., 2003).

In the present study, eating undercooked meat was a major risk factor in the transmission of $T$. gondii infection which is in agreement with several studies conducted elsewhere (Koskiniemi et al. 1989; Lopez-Castillo et al., 2005; Sroka et al., 2010; Alvarado-Esquivel et al., 2011). It is possible 
that one of the sources of $T$. gondii infection in this study population is likely to be from eating meat with tachyzoites or bradyzoites hence leading to the infection transmission. Although in the current study eating in restaurants was more associated with a higher sero-prevalence of anti-T. gondii antibodies than those who did not, the difference was not statistically significant. However, some studies have demonstrated significant association between anti-T. gondii antibody seropositivity and the habit of eating in restaurants (Montoya \& Liesenfeld, 2004).

There were no significant differences in sero-prevalence of anti- $T$. gondii antibodies in relation to tasting food while cooking, history of previous abortion, HIV status and being exposed to any kind of knowledge about toxoplasmosis. The absence of a significant relationship between the prevalence of Toxoplasma infection among pregnant women in Kigali and many of the factors explored in this study, does not rule out the possibility of these factors having some influence on the transmission of toxoplasmosis. Probably a larger study needs to be undertaken to explore further the role of the various risk factors for $T$. gondii.

From the findings of the present study, drinking untreated water and eating undercooked meat are the most important risk factors for T. gondii infection in Kigali. Further studies on the burden of maternal and congenital toxoplasmosis should be carried out in the country in order to advise policy on possible needs of instituting control programmes. Routine screening of $T$. gondii infections during antenatal care should be considered in Rwanda as the main strategy to minimize congenital toxoplasmosis.

\section{Competing interests}

The authors declare that they have no competing interests.

\section{Authors' contributions}

EM conceived the study, collected the data and drafted the paper. JCSN, supported the data analysis and drafted the initial manuscript. KN, KJN, WJ supervised the execution of the study and edited the manuscript. All authors read and approved the final version of the manuscript.

\section{Acknowledgements}

We are grateful to the Department of Medical Microbiology of the University of Nairobi and Rwanda Biomedical Centre/National Reference Laboratory for provision of the laboratory facilities and technical assistance. Special thanks to Mr. Paolo Paganin (Africhem-Rwanda Ltd) who supported efficiently in procurement of laboratory kits used in this study. To the Health Centres of Muhima, Biryogo, Cor-Unum and Nyarugunga for their enthusiasm and assistance in recruitment of the study subjects. Many thanks to the pregnant women who accepted to participate in this study. This study received financial assistance from the Government of Rwanda through the Ministry of Health.

\section{References}

Al-Mohammad, H.I., Amin, T.T,. Balaha, M.H. \& Al-Moghannum, M. S. (2010) Toxoplasmosis among the pregnant women attending a Saudi maternity hospital: seroprevalence and possible risk factors. Annals of Tropical Medicine and Parasitology 104: 493-504.

Alsammani, M.A. (2014) Sero-epidemiology and risk factors for Toxoplasma gondii among pregnant women in Arab and African countries. Journal of Parasitic Diseases 40: 569-579.

Alvarado-Esquivel, C., Estrada-Martinez, S. \& Liesenfeld, O. (2011) Toxoplasma gondii infection in workers occupationally exposed to unwashed raw fruits and vegetables: a case control seroprevalence study. Parasites and Vectors 4: 235. 
Ayi, I., Edu, S.A.A., Apea-Kubi, K.A., Boamah, D., Bosompem K.M. \& Edoh, D. (2009) Seroepidemiology of toxoplasmosis amongst pregnant women in the greater accra region of Ghana. Ghana Medical Journal 43: 107-114.

Bahia-Oliveira, L.M. G. Jones, J.L., Azevedo-Silva, J., Alves, C.C.F., Oréfice, F. \& Addiss, D. (2003) Highly Endemic, Waterborne Toxoplasmosis in North Rio de Janeiro State, Brazil. Emerging Infectious Diseases 9: 55-62.

Cochran, W.G. (1963) Sampling Techniques, 2nd Ed., New York: John Wiley and Sons, Inc.

Deji-Agboola, A.M., Busari, O.S., Osinupebi, O.A. \& Amoo, A.O.J. (2011) Seroprevalence of Toxoplasma gondii antibodies among pregnant women attending antenatal clinic of Federal Medical Center, Lagos, Nigeria. International Journal of Biological \& Medical Research 2: 11351139 .

Dubey, J.P. \& Jones, J.L. (2008) Toxoplasma gondii infection in humans and animals in the United States. International Journal of Parasitology 38: 1257-1278.

Foulon, W., Pinon, J.M., Stray-Pedersen, B., Pollak, A., Lappalainen, M., Decoster, A., Villena, I., Jenum, P.A., Hayde, M. \& Naessens, A. (1999) Prenatal diagnosis of congenital toxoplasmosis: a multicenter evaluation of different diagnostic parameters. American Journal of Obstetrics and Gynecology 181: 843-847.

Gascon, J., Torres-Rodriguez, J.M., Soldevila, M. \& Merlos, A.M. (1989) Seroepidemiology of toxoplasmosis in 2 communities of Rwanda, Central Africa. Revista do Instituto de Medicina Tropical de São Paulo 31: 399-402.

Gibbs, R. S. (2002) The origins of stillbirth: infectious diseases. Seminars in Perinatology 26: 75-78.

Goldenberg, R.L. \& Thompson, C. (2003) The infectious origins of stillbirth. American Journal of Obstetrics and Gynecology 189: 861-873.

Hegab, S.M. \& Al-Mutawa, S.A. (2003) Immunopathogenesis of toxoplasmosis. Clinical and Experimental Medicine 3: 84-105.

Ishaku, B., Ajogi, I., Umoh, J., Lawal, I. \& Randawa, A. (2009) Seroprevalence and risk factors for Toxoplasma gondii infection among antenatal women in Zaria, Nigeria. Research Journal of Medicine and Medical Sciences 4: 483-488.

Jones, J.L., Kruszon-Moran, D., Wilson, M., McQuillan, G., Navin, T. \& McAuley, J. B. (2001) Toxoplasma gondii infection in the United States: seroprevalence and risk factors. American Journal of Epidemiology 154: 357-365.

Koskiniemi, M., Lappalainen, M. \& Hedman, K. (1989) Toxoplasmosis needs evaluation. An overview and proposals. American Journal of Diseases of Children 143: 724-728.

Lopez-Castillo, C.A., Diaz-Ramirez, J. \& Gomez-Marin, J.E. (2005) Risk factors for Toxoplasma gondii infection in pregnant women in Armenia, Colombia. Revista de Salud Publica (Bogota) 7: 180190.

Markovich, M. P., Shohat, T., Riklis, I., Avni, R., Yujelevski-Rozenblit, D., Bassal, R., Cohen, D.M. \& Rorman, E. (2014) Seroepidemiology of Toxoplasma gondii infection in the Israeli population. Epidemiology and Infection 142: 149-155.

Montoya, J. G. \& Liesenfeld, O. (2004) Toxoplasmosis. Lancet 363 (9425): 1965-1976.

Mwambe, B., Mshana, S.E.. Kidenya, B.R., Massinde, A.N., Mazigo, H.D., Michael, D., Majinge, C. \& Gross, U. (2013) Sero-prevalence and factors associated with Toxoplasma gondii infection among pregnant women attending antenatal care in Mwanza, Tanzania. Parasites and Vectors 6: 222.

Pappas, G., Roussos, N. \& Falagas, M. E. (2009) Toxoplasmosis snapshots: global status of Toxoplasma gondii seroprevalence and implications for pregnancy and congenital toxoplasmosis. International Journal of Parasitology 39: 1385-1394.

Petersen, E., Vesco, G., Villari, S. \& Buffolano, W. (2010) What do we know about risk factors for infection in humans with Toxoplasma gondii and how can we prevent infections? Zoonoses and Public Health 57: 8-17. 
Rosso, F., Les, Agudelo, J.T., Villalobos, C., Chaves, J.A., Tunubala, G.A., Messa, A., Remington J.S. \& Montoya, J.G. (2008) Prevalence of infection with Toxoplasma gondii among pregnant women in Cali, Colombia, South America. American Journal of Tropical Medicine and Hygiene 78: 504-508.

Sroka, J., Wojcik-Fatla, A., Szymanska, J., Dutkiewicz, J., Zajac, V. \& Zwolinski, J. (2010) The occurrence of Toxoplasma gondii infection in people and animals from rural environment of Lublin region - estimate of potential role of water as a source of infection. Annals of Agricultural and Environmental Medicine 17: 125-132.

Tenter, A.M., Heckeroth, A.R. \& Weiss, L.M. (2000) Toxoplasma gondii: from animals to humans. International Journal for Parasitology 30: 1217-58. 